\title{
PENGARUH PENAMBAHAN LIMBAH PLASTIK BEKAS TERHADAP KARAKTERISTIK KEKUATAN TARIK DAN KEKUATAN BENDING MATERIAL POLIMER KOMERSIL
}

\author{
Sujita*, Sajuri Gunawan Hadi** \\ *Dosen, Jurusan Teknik Mesin Universitas Mataram NTB, \\ Jl. Majapahit No. 62 Mataram. \\ **Mahasiswa, Jurusan Teknik Mesin Fakultas Teknik Universitas Mataram \\ JI. Majapahit No. 62 Mataram, Nusa Tenggara Barat \\ Telpon. (0370) 636126, Fax. (0370) 636523
}

\begin{abstract}
Polyester, epoxy and polyurethane composites are widely used for the matrix. The use of composite materials in the manufacturing industry as well as many studies of composites by utilizing plastic powder and the lack of studies directly comparing the tensile strength and bending properties of composite plastic powder to the treatment of the same fiber. The purpose of this study was to determine the tensile and bending strength of the composite material of polyester, epoxy, and polyurethane with reinforcing plastic powder by varying the volume fraction.

In this study, the material used is plastic powder, with a size of $8 \mathrm{~mm}$ and the preparation of chopped random fibers, with a fiber volume fraction (0\% / 100\%, 5\% / 95\%, 10\% / 90\%, $20 \%$ / 80\%, $30 \%$ / 70\%, 40\% / 60, 50\% / 50\%, 60\% / 40\%, and 70\% / 30\%), using polyester resin, epoxy, and polyurethane as matriknya. Comparison of epoxy resin and polyurethane that is one to one, while for polyester using the catalyst of $2 \%$. Tensile testing with ASTM D 3039, and bending test were conducted with ASTM D 790.

The results of tensile testing tensile strength values obtained by variation of the highest volume fraction of $0 \%$ is owned by a composite plastic powder with $100 \%$ polyester resin with a value of $35.22 \mathrm{MPa}$, followed by a variation of the volume fraction of the composite with $0 \%$ plastic powder with $100 \%$ epoxy resin with the strength values pull of $6.40 \mathrm{MPa}$. While bending test results obtained the highest bending strength values held by the variation of volume fraction of the composite $0 \%$ plastic powder with $100 \%$ polyester resin with a value of $66.985 \mathrm{MPa}$, then successively followed by the composite with the highest volume fraction variation possessed by $30 \%$ of composite powders plastic with $70 \%$ epoxy resin with a value of $42.078 \mathrm{MPa}$ bending strength, for a volume fraction of $50 \%$ variation of plastic powder with $50 \%$ polyurethane resin to obtain the highest value of bending strength of $6.963 \mathrm{MPa}$.
\end{abstract}

Keywords: composite, tensile strength, bending strength, plastic powder, polyester resins, epoxy, and polyurethane.

\section{PENDAHULUAN}

Seperti diketahui, plastik merupakan bahan kebutuhan yang banyak dipergunakan dalam kehidupan manusia modern. Akan tetapi sisa sampah dari Plastik bisa menjadi permasalahan tersendiri bagi lingkungan. Saat ini, penggunaan plastik sangat luas karena plastik merupakan bahan yang praktis, kuat, tahan lama, ringan dan dapat dibentuk apas aja. Plastik merupakan polimer, namun masyarakat umum lebih mengenal polimer dengan nama plastik. Polimer adalah molekul raksasa yang biasanya memiliki bobot molekul tinggi, dibangun dari pengulangan unit-unit. Molekul sederhana yang membentuk unitunit ulangan ini dinamakan monomer. Sedangkan reaksi pembentukan polimer dikenal dengan istilah polimerisasi (Hart, 1983).

Zat yang terkandung didalam plastik salah satuaya adalah vinilklorida dan akrilonitril. Zat ini dapat menyebabkan kanker tiroid, uterus dan lever pada hewan. Juga dapat menimbulkan cacat lahir pada tikus yang memakannya. Monomer lain pada plastik seperti akrilat, stirena dan metakrilat dapat menimbulkan iritasi pada saluran pencernaan. Plastik merupakan bahan anorganik buatan yang tersusun dari bahanbahan kimia yang cukup berbahaya bagi lingkungan. Untuk menguraikan sampah plastik itu sendiri membutuhkan kurang lebih 100 hingga 500 tahun agar dapat terdegradasi dengan sempurna (Arcana, 2009). 
Hoekstra (2001) meneliti sifat mekanik plastik HDPE yang diisi dengan filler serbuk kaca. Penelitian dilakukan dengan variasi penambahan serbuk kaca hingga $40 \%$ massa total material, dengan dua jenis ukuran serbuk karet. Pencampuran dilakukan dengan penambahan binder gel. Hasil penelitian menunjukkan bahwa penambahan komposisi serbuk kaca dengan ukuran yang lebih kecil akan meningkatkan kekuatan impak dan flexural modulus material campuran.

Nurdin (2008) meneliti pengaruh jenis serat pada komposit terhadap kekuatan tarik bahan komposit polimer/serat gelas. Hasil penelitian tersebut menunjukkan bahwa jenis serat E-glass dengan tipe chopped strand mat memiliki kekuatan tarik sebesar 75,55 $\mathrm{MPa}$. Dari beberapa penelitian tersebut belum ada yang membandingkan karakteristik komposit antara komposit yang berpenguat serat bambu apus dan komposit yang berpenguat serat gelas dengan tipe sama yaitu chopped strand matdengan proses yang sama dalam satu lingkup penelitian. Hal ini mendorong penulis untuk melakukan penelitian lebih lanjut.

\section{LANDASAN TEORI}

\subsection{Komposit}

a. Pengertian Komposit

Kata komposit berasal dari kata "to compose" yang berarti menyusun atau menggabung. Secara sederhana bahan komposit berarti suatu bahan yang merupakan gabungan atau campuran dari dua material atau lebih pada skala makroskopis untuk membentuk material ketiga yang lebih bermanfaat. Jika perpaduan ini terjadi dalam skala makroskopis, maka disebut sebagai komposit. Sedangkan jika perpaduan ini bersifat mikroskopis, maka disebut sebagai paduan (alloy). Paduan adalah kombinasi antara dua bahan atau lebih dimana bahanbahan tersebut terjadi peleburan sedangkan komposit adalah kombinasi terekayasa dari dua atau lebih bahan yang mempunyai sifatsifat seperti yang diinginkan dengan cara kombinasi sistematik pada kandungankandungan yang berbeda tersebut (Vlack, 1994).

b. Unsur Penyusun Komposit

Pada umumnya bahan komposit terdiri dari dua unsur, yaitu serat (fiber) dan bahan pengikat serat tersebut yang disebut matrik

\section{Serat}

Salah satu unsur penyusun bahan komposit adalah serat. Serat inilah yang terutama menentukan karakteristik bahan komposit, seperti kekakuan, kekuatan serta sifat-sifat mekanik lainnya. Serat inilah yang menahan sebagian besar gaya-gaya yang bekerja pada bahan komposit.

2. Matriks

Matriks dalam susunan komposit bertugas melindungi dan mengikat serat agar dapat bekerja dengan baik.

c. Tipe komposit serat

Untuk memperoleh komposit yang kuat harus dapat menempatkan serat dengan benar.

d. Faktor yang mempengaruhi performa komposit.

Penelitian yang menggabungkan antara matrik dan serat harus memperhatikan beberapa faktor yang mempengaruhi performa fiber-matriks composite antara lain.

1. Faktor serat

Serat adalah bahan pengisi matrik yang digunakan untuk dapat memperbaiki sifat dan strukur matrik yang tidak dimilikinya, juga diharapkan mampu menjadi bahan penguat matrik pada komposit untuk menehan gaya yang terjadi.

2. Letak serat

Dalam pembuatan komposit tata letak dan arah serat dalam matrik yang akan menentukan kekuatan mekanik komposit, dimana letak dan arah dapat mempengaruhi kinerja komposit tersebut.

3. Panjang serat

Panjang serat dalam pembuatan komposit serat pada matrik sangat berpengaruh terhadap kekuatan.

4. Bentuk serat

Bentuk serat yang digunakan untuk pembuatan komposit tidak begitu mempengaruhi, yang mempengaruhi adalah diameter seratnya.

5. Faktor matrik

Matrik dalam komposit berfungsi sebagai bahan yang mengikat serat menjadi sebuah unit struktur, melindungi dari perusakan eksternal, meneruskan atau memindahkan beban eksternal pada bidang geser antara serat dan matrik, sehingga matrik dan serat saling berhubungan.

6. Faktor ikatan fiber-matrik

Komposit serat yang baik harus mampu untuk menyerap matrik yang memudahkan terjadinya pertemuan antara dua fase.

7. Katalis 
Katalis ini digunakan untuk membantu proses pengeringan resin dan serat dalam komposit.

\subsection{Jenis Limbah Plastik Polipropilena} (PP)

Polipropilena atau polipropena (PP) adalah sebuah polimer termo-plastik yang dibuat oleh industri kimia dan digunakan dalam berbagai aplikasi, diantaranya pengemasan, tekstil (contohnya tali, pakaian dalam termal, dan karpet), alat tulis, berbagai tipe wadah terpakaikan ulang serta bagian plastik, perlengkapan labolatorium, pengeras suara, komponen otomotif, dan uang kertas polimer. Polimer adisi yang terbuat dari propilena monomer, permukaannya tidak rata serta memiliki sifat resistan yang tidak biasa terhadap kebanyakan pelarut kimia, basa dan asam.

\subsection{Resin Polyester}

Polyester Resin adalah cairan yang akan menyembuhkan ke padat ketika pengeras ditambahkan. Telah diformulasikan khusus untuk menyembuhkan pada suhu kamar. Pengeras MEKP (Methyl Ethyl Ketone Peroksid) ditambahkan untuk menyembuhkan, atau mengeras resin. Pengeras MEKP untuk resin polyester, sering disebut sebagai katalis datang dalam keciltabung plastik atau botol dengan pengukuran lulus ditandai pada mereka.

\subsection{Resin Epoxy}

Perekat ini merupakan produk sintetik termoset dari reaksi resin epoxy dengan zat pengeras. Dapat diperoleh dalam bentuk sistem satu atau dua komponen. Sistem satu komponen meliputi resin cair bebas, larutan, pasta resin cair, bubuk, pellet, dan pasta. Sistem dua komponen terdiri atas resin zat curing yang dicampur saat akan digunakan. Sistem juga mengandung pemlastik, pengecer reaktif, filler, pigmen dan zat resin lain.

\subsection{Resin Polyurethane}

Polyurethane memiliki banyak kegunaan, diantaranya sekitar $70 \%$ digunakan sebagai busa (Foam), selebihnya sebagai bahan elastomer, lem dan pelapis. Polyurethane merupakan bahan polimer yang mempunyai ciri khas adanya gugus fungsi urethane (-NHCOO) dalam rantai utama polimer. Gugus fungsi urethane dihasilkan dari reaksi antara senyawa yang mengandung gugus hidroksil $(-\mathrm{OH})$ yang biasa disebut polyol dengan senyawa yang mengandung gugus isocyanate (-NCO-).

\subsection{Uji Kekuatan Tarik Menggunakan Standar ASTM 3039}

Pengujian tarik dilakukan terhadap spesimen batang uji yang standar. Bahan yang akan diuji mula-mula dibuat menjadi batang uji dengan bentuk sesuai dengan suatu standar. Pada bagian tengah dari batang uji merupakan bagian yang menerima tegangan, pada bagian ini diukur panjang batang uji, yaitu bagian yang dianggap menerima pengaruh dari pembebanan. Bagian inilah yang selalu diukur pada proses pengujian.Batang uji dipasang pada mesin tarik, dijepit dengan pencekaman pada mesin tarik pada ujungujungnya dan ditarik kearah memanjang secara perlahan. Selama penarikan, setiap saat dicatat atau tercatat dengan grafik yang tersedia pada mesin tarik. Penarikan berlangsung terus sampai batang uji putus.

Data yang diperoleh dari mesin tarik dinyatakan dalam grafik tegangan-regangan (stess-strain) atau disebut juga diagram tarik.

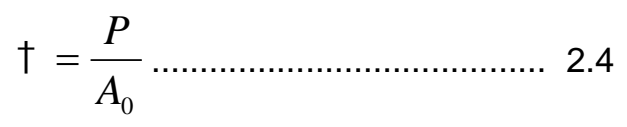

dimana :

$\sigma=$ Tegangan tarik $\left(\mathrm{kg} / \mathrm{mm}^{2}\right)$

$\mathrm{P}=$ Beban tarik $(\mathrm{kg})$

$\mathrm{A}_{0}=$ Luas penampang mula-mula $\left(\mathrm{mm}^{2}\right)$

$\varepsilon=\frac{L_{1}-L_{0}}{L_{0}}$ sehingga

$E=\frac{\sigma}{\varepsilon}$

dimana :

$E=$ Modulus Elastisitas

$\mathrm{L}_{1}=$ Panjang setelah dibebani.

$\mathrm{L}_{0}=$ Panjang mula-mula sebelum dibebani.

$\sigma=$ Tegangan tarik $\left(\mathrm{kg} / \mathrm{mm}^{2}\right)$

$\varepsilon=$ Regangan tarik

\subsection{Uji Bending}

Pengujian bending adalah salah satu pengujian yang sudah lama dipakai karena dapat dilakukan pada bahan uji berbentuk standar dan tidak perlu menggunakan mesin uji khusus atau mesin uji seperti biasanya (Supardi, 1999).

Kekuatan bending suatu material dapat dihitung dengan persamaan berikut :

$$
\sigma=\frac{M c}{I}
$$

Keterangan:

$\sigma=$ Kekuatan bending (Mpa)

$\mathrm{M}=\operatorname{Momen}(\mathrm{N} \cdot \mathrm{mm})$

$\mathrm{I}=$ Inersia $\left(\mathrm{mm}^{4}\right)$

$\mathrm{c}=$ Jarak dari sumbu netral ke 
tegangan serat ( $\mathrm{mm})$

Pada material yang homogen pengujian batang sederhana dengan dua titik dudukan dan pembebanan pada tengahtengah batang uji (three point bending), maka tegangan maksimum dapat dihitung dengan persamaan berikut (ASTM D 790):

$$
\begin{aligned}
& \sigma=\frac{3 P L}{2 b d^{2}} \\
& \text { Keterangan: } \\
& \sigma=\text { Kekuatan bending (Mpa) } \\
& \mathrm{P}=\text { Beban maksimal }(\mathrm{N}) \\
& \mathrm{L}=\text { Panjang span }(\mathrm{mm}) \\
& \mathrm{b}=\text { lebar batang uji }(\mathrm{mm}) \\
& \mathrm{d}=\text { tebal batang uji }(\mathrm{mm})
\end{aligned}
$$

\section{METODOLOGI PENELITIAN}

3.1 Proses persiapan Serbuk plastic

a. Pembelian cacahan plastik bekas botol plastik berwarna bening.

b. Dicuci sampai bersih supaya bebas dari kotoron yang ada.

c. Melakukan pencacahan plastik menggunakan parang agar sampai pada ukuran yang ditentukan untuk siap digunakan.

d. Melakukan pengayakan agar supaya terpisahnya ukuran cacahan yang ditentukan.

e. Penjemuran plastik untuk menghilangkan kadar air dibawah sinar matahari.

f. Pengambilan serbuk plastik untuk siap digunakan.

\subsection{Langkah Pengujian}

\subsubsection{Pengujian Tarik (Tensile Test)}

Pada pengujian tarik menggunakan Universal Testing Machine (UTM) dalam kondisi suhu kamar lingkungan laboraturium. Pengujian tarik dilakukan terhadap spesimen/batang uji yang sudah standar. Pada bagian tengah dari spesimen uji (pada bagian yang paralel) merupakan bagian yang menerima tegangan yang uniform, dan pada bagian ini diukur "panjang uji" (gauge length) yaitu bagian yang dianggap menerima pengaruh dari pembebanan. Bagian ini yang selalu diukur panjangnya selama proses pengujian.

Langkah pertama dalam pengujian tarik adalah memasang spesimen yang telah disiapkan pada mesin uji tarik, dijepit dengan pencekam pada ujung-ujungnya dan diberi beban tarik ke arah memanjang secara perlahan-lahan dengan gaya nol kemudian bertambah hingga benda itu putus. Pada saat pengujian gaya atau tegangan dan perubahan panjang batang dapat dilihat dalam bentuk kurva regangan.

\subsubsection{Pengujian Bending}

Pengujian kekuatan bending dilakukan menggunakan alat uji bending dengan merak torse universal testing machine tipe AMU-5-DE. Dengan memberikan gaya lintang pada spesimen yang berupa pelat, tegangan bending dinyatakan oleh besarnya gaya lintang tiap satu satuan luas spesimen. Bentuk spesimen mengacu pada standar ASTM D 790. Dimana lebarnya : $25,4 \mathrm{~mm}$, tinggi : $6 \mathrm{~mm}$, dan panjang :152,4 mm.

Spesimen dibuat berdasarkan standar ASTM D790 dengan ukuran $152.4 \mathrm{~mm} \mathrm{x}$ $25.4 \mathrm{~mm} \times 6 \mathrm{~mm}$. bentuk spesimen dapat dilihat pada gambar dibawah ini :

\section{HASIL DAN PEMBAHASAN}

Pada penelitian ini, pembahasan utamanya diarahkan pada pengujian kekuatan Tarik dilakukan terhadap spesimen uji Tarik sesuai dengan ASTM D3039, pengujian dilakukan pada suhu kamar dan kondisi lingkungan Laboratorium Logam Teknik Mesin Universitas Mataram. Uji tarik dilakukan dengan tujuan untuk mengetahui sifat-sifat mekanik dan karakteristik kekuatan tarik komposit serbuk plastik dengan matriks resin poliyester, epoxy dan polyurethane pada variasi letak serat acak.

\subsection{Uji kekuatan tarik}

4.1.1 Uji kekuatan tarik serbuk plastik dengan resin polyester

Pengujian kekuatan tarik dilakukan di laboratorium Metalorgi Teknik Mesin Universitas Mataram. Uji tarik dilakukan dengan tujuan untuk mengetahui seberapa besar pengaruh variasi letak serat acak pada komposit dengan Variasi fraksi volume serbuk plastik dengan resin $0 \% / 100 \%$, 5\%/95\%, 10\%/90\%, 20\%/80\%, 30\%/70\%, $40 \% / 60 \%, \quad 50 \% / 50 \%, \quad 60 \% / 40 \%$, dan $70 \% / 30 \%$. Sehingga di peroleh data pengujian tarik terhadap komposit serbuk plastik dari limbah dengan matrik polyester seperti dalam grafik dibawah ini : 


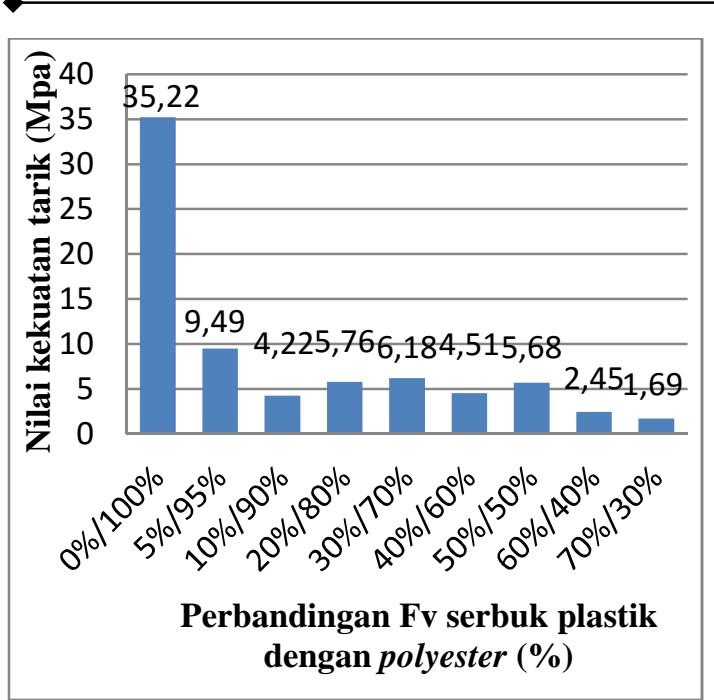

Gambar 1. Grafik perbandingan variasi fraksi volume serbuk plastik dengan resin polyester dengan kekuatan tarik rata-rata komposit.

Seperti yang ditunjukan pada gambar 1. serbuk plastik dengan variasi fraksi volume $0 \%$ serbuk plastik dengan $100 \%$ polyester dengan variasi letak serat acak memiliki kekuatan tarik rata-rata sebesar 35.22 Mpa memiliki nilai tertinggi dibandingkan dengan variasi fraksi volume pada grafik perbandingan diatas, pada variasi fraksi volume $40 \%$ serbuk plastik dengan $60 \%$ resin polyester mendapatkan nilai rata-rata 4.51 Mpa. Pada grafik perbandingan diatas menjelaskan bahwa yang memiliki nilai yang paling terendah jatuh pada variasi fraksi volume $70 \%$ serbuk plastik dengan $30 \%$ resin polyester dengan nilai kekuatan tarik rata-rata adalah 1.69 Mpa.

\subsubsection{Uji Kekuatan Tarik Serbuk Plastik Dengan Resin Epoxy}

Pada pengujian spesimen dengan bahan serbuk plastik dapat diketahui nilai kekuatan tarik dengan variasi fraksi volume serbuk plastik dengan resin epoxy $0 \% / 100 \%$, $5 \% / 95 \%, \quad 10 \% / 90 \%, \quad 20 \% / 80 \%, 30 \% / 70 \%$, dan $40 \% / 60 \%$.

Grafik perbandingan kekuatan tarik dengan variasi fraksi volume serbuk plastik dengan resin epoxy mengambil kekuatan tarik rata-rata dari setiap variasi serbuk plastik dengan resin untuk tiga kali pengulangan. Sehingga di peroleh perbandingan besarnya kekuatan tarik pada masing-masing variasi serbuk plastik dapat membedakan di variasi mana nilai kekuatan tarik tertinggi dan terendah, seperti terlihat pada gambar berikut ini:

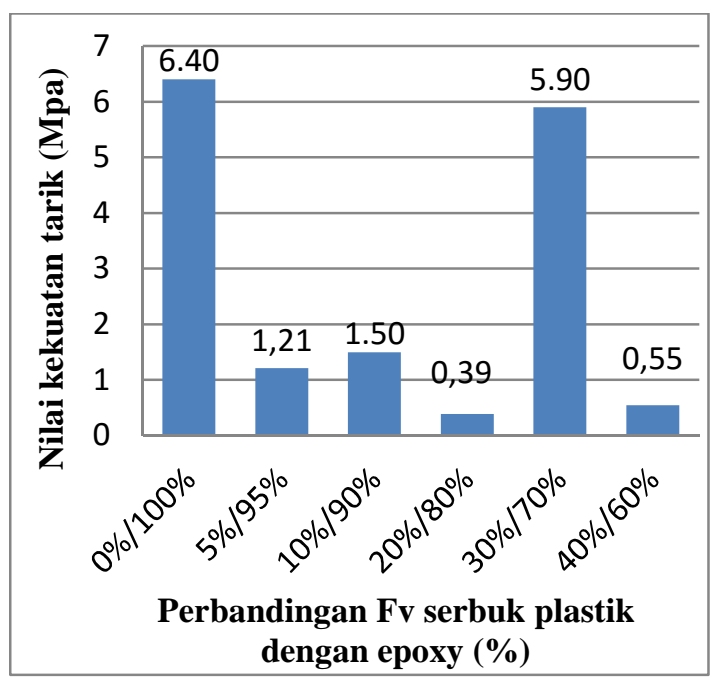

Gambar 2. Grafik perbandingan variasi fraksi volume serbuk plastik dengan resin epoxy dengan kekuatan tarik rata-rata komposit.

Dari gambar 4. diatas bahwa nilai kekuatan tarik dari variasi fraksi volume $0 \%$ serbuk plastik dengan 100\% resin epoxy, yang memiliki kekuatan tarik rata-rata sebesar 6.40 Mpa merupakan nilai tertinggi dari hasil pengujian tarik, sedangkan pada variasi fraksi volume $20 \%$ serbuk plastik dengan $80 \%$ resin epoxy memiliki nilai terendah dari enam variasi dengan kekuatan tarik rata-rata sebesar 0.39 Mpa. Jika dibandingkan nilai kekuatan tarik rata-rata resin polyester dengan resin epoxy, maka nilai kekuatan tarik resin polyester lebih tinggi dari pada resin epoxy, karena komposit dari serbuk plastik dengan resin polyester tersebut bersifat getas sehingga kekuatan tariknya tinggi sedangkan spesimen dari resin epoxy bersifat lunak sehingga nilai kekuatan tarik rata-rata epoxy dibawah nilai kekuatan tarik rata-rata polyester.

\subsubsection{Pengujian Kekuatan Bending}

Uji bending dilakukan di laboratorium Metalorgi Teknik Mesin Universitas Mataram. dengan tujuan untuk mengetahui seberapa besar pengaruh dengan Variasi fraksi volume serbuk plastik dengan resin $0 \% / 100 \%, \quad 5 \% / 95 \%, \quad 10 \% / 90 \%, \quad 20 \% / 80 \%$, $30 \% / 70 \%, 40 \% / 60 \%, 50 \% / 50 \%, 60 \% / 40 \%$, dan $70 \% / 30 \%$, serbuk plastik dengan resin polyester, epoxy dan polyurethane dengan menggunakan mesin uji bending ASTM D 790.

4.2.1 Uji kekuatan bending serbuk plastik dengan resin polyester dan polyurethane

Data hasil uji bending yang diambil merupakan kekuatan bending rata-rata dari tiga spesimen. Data-data dari pengujian 
kemudian di masukkan kedalam persamaan 2.2 sehingga di peroleh data pengujian bending terhadap komposit serbuk plastik dengan resin polyester.

Grafik perbandingan kekuatan bending dengan variasi fraksi volume serbuk plastik dengan resin polyester, epoxy dan polyurethane 0\%/100\%, 5\%/95\%, 10\%/90\%, $20 \% / 80 \%$, 30\%/70\%, 40\%/60\%, 50\%/50\%, $60 \% / 40 \%$, dan $70 \% / 30 \%$, komposit dari serbuk plastik, dengan mengambil kekuatan bending rata-rata dari setiap variasi fraksi volume untuk tiga kali pengulangan. Sehingga diperoleh perbandingan besarnya kekuatan bending pada masing-masing variasi fraksi volume, seperti terlihat pada gambar 5. berikut ini:

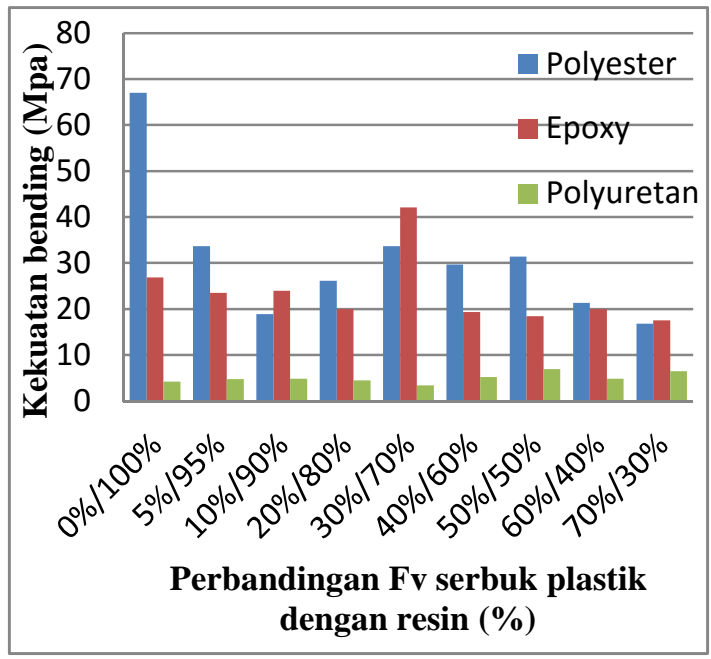

Gambar 3. Grafik perbandingan variasi fraksi volume serbuk plastik dengan resin dengan kekuatan bending rata-rata komposit

Pada gambar 5. menunjukkan bahwa perbandingan variasi fraksi volume serbuk plastik dengan resin polyester, epoxy dan polyurethane yaitu $0 \% / 100 \%, \quad 5 \% / 95 \%$, 10\%/90\%, 20\%/80\%, 30\%/70\%, 40\%/60\%, $50 \% / 50 \%$, 60\%/40\%, dan 70\%/30\%. Pada variasi fraksi volume $0 \%$ serbuk plastik dengan $100 \%$ resin, untuk polyester mendapatkan nilai kekuatan bending ratarata tertiggi sebesar 66.985 Mpa, epoxy mendapatkan nilai kekuatan bending ratarata sebesar 26.874 Mpa, sedangkan untuk polyurethane mendapatkan nilai kekuatan bending rata-rata sebesar 4.210 Mpa.

\section{KESIMPULAN DAN SARAN \\ 5.1. Kesimpulan}

Dari penelitian pengujian tarik disimpulkan bahwa kekuatan tarik komposit dengan variasi fraksi volume serbuk plastik dengan resin dari sembilan variasi. Maka nilai kekuatan tarik serbuk plastik dengan resin tertinggi didapatkan pada variasi fraksi volume $0 \%$ serbuk plastik dengan 100\% resin polyester dengan memperoleh nilai kekuatan tarik sebesar 35.22 Mpa.

Sedangkan pada variasi fraksi volume $0 \%$ serbuk plastik dengan $100 \%$ resin epoxy memperoleh nilai kekuatan tarik rata-rata tertinggi sebesar 6.40 Mpa. Untuk nilai kekuatan tarik terendah diperoleh pada variasi fraksi $70 \%$ serbuk plastik dengan $30 \%$ resin polyester, memperoleh nilai kekuatan tarik rata-rata sebesar $1.69 \mathrm{Mpa}$, pada variasi fraksi volume $20 \%$ serbuk plastik dengan $80 \%$ resin epoxy memperoleh nilai kekuatan tarik terendah sebesar 0.39 Mpa.

Pada pengujian bending yang telah dilakukan, maka dapat disimpulkan bahwa kekuatan komposit dipengaruhi oleh serbuk plastik dan resin yang digunakan. Kekuatan bending komposit serbuk plastik dengan variasi fraksi volume serbuk plastik dengan resin polyester, epoxy, dan polyurethane dengan sembilan jenis variasi. Maka nilai kekuatan bending tertinggi diperoleh pada variasi fraksi volume $0 \%$ serbuk plastik dengan $100 \%$ resin polyester memperoleh nilai kekuatan bending rata-rata sebesar 66.985 Mpa. Untuk 40\% serbuk plastik dengan $60 \%$ resin epoxy memperoleh nilai kekuatan bending tertinggi sebesar 42.078 Mpa, sedangkan pada variasi fraksi volume $50 \%$ serbuk plastik dengan $50 \%$ resin polyurethane memperoleh nilai kekuatan bending rata-rata sebesar 6.963 Mpa.

\subsection{Saran}

Berdasarkan penelitian yang dilakukan, maka saran-saran yang dapat disampaikan adalah sebagai berikut :

1. Penelitian dapat di kembangkan kembali dengan menggunakan serat alam lainya dengan teknik yang berbeda.

2. Pada waktu pembuatan spesimen hendaknya peneliti bisa untuk meminimalisasi cacat-cacat pada spesimen yang nantinya akan berpengaruh terhadap hasil dari pengujian tersebut.

3. Peneliti hendaknya memperhatikan dengan benar kepresisian dari ukuran spesimen yang akan diuji sehingga nantinya memperoleh hasil yang baik.

\section{DAFTAR PUSTAKA}

[1] Arcana, I. M., 2009, Perang Melawan Sampah http://www.kompas.com(21 Oktober 2009) 
[2] ASTM, 2004, Standards Test Method for Tensile Properties of Polymer Matrix Composite Materials, Volume 15.03, October 2005

[3] Hart, 1983, Organic Chemistry, a Short Course. 6th Ed. Michigan : Houghton Mifflin.

[4] Hoekstra, N. L., 2001, Crushed Recycled Glass as A Stiffening Agent For HDPE compared to.

[5] Nurdin, H., 2008, Pengaruh Penggunaan Jenis Serat Pada Komposit Polimer Terhadap Kekuatan Tarik, Zona Teknik ISSN. Volume 3 No.2 : 143-150

[6] Supardi, E, 1999, Pengujian Logam, Angkasa Bandung, Bandung.

[7] Vlack, L. H. V., 1994, Ilmu dan Teknologi Bahan (IImu Logam dan Bukan Logam) Edisi Kelima. Terjemahan Sriati Djaprie. Erlangga: Jakarta. 